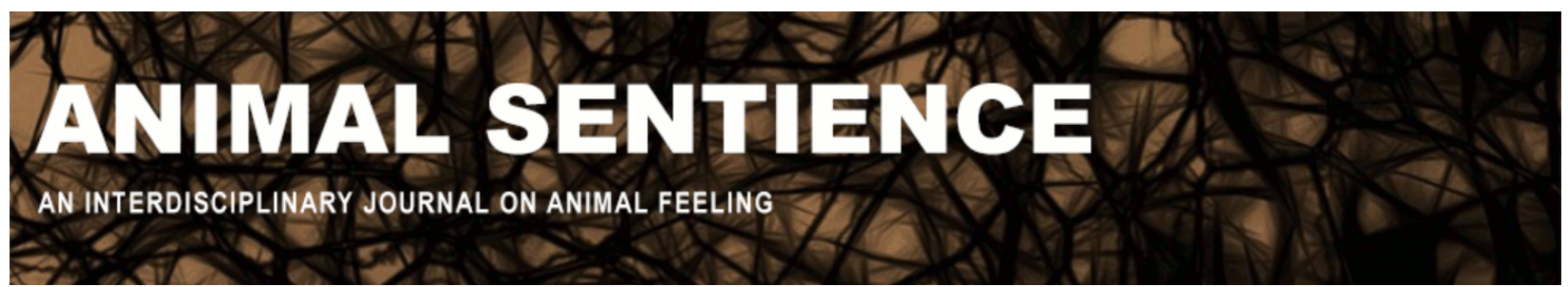

Webb, Christine E. and de Waal, Frans B. M. (2018) Situating the study of jealousy in the context of social relationships. Animal Sentience 22(22)

DOI: $10.51291 / 2377-7478.1371$

Date of submission: 2018-09-15

Date of acceptance: 2018-09-27

(c) 


\title{
Situating the study of jealousy in the context of social relationships
}

Commentary on Cook et al. on Dog Jealousy

\author{
Christine E. Webb \& Frans B. M. de Waal \\ Department of Psychology, Emory University
}

\begin{abstract}
Whereas the feelings of other beings are private and may always remain so, emotions are simultaneously manifested in behavior, physiology, and other observables. Nonetheless, uncertainty about whether emotions can be studied adequately across species has promoted skepticism about their very presence in other parts of the animal kingdom. Studying social emotions like jealousy in the context of the social relationships in which they arise, as has been done in the case of animal empathy, may help dispel this skepticism. Empathy in other species came to be accepted partly because of the behavioral similarities between its expression in nonhuman animals and humans, and partly because of the neurological parallels. Non-invasive brain imaging results like those reported in the target article can thus help integrate human and animal emotions within an evolutionary framework - but the social context underlies precise definitions of the phenomenon.
\end{abstract}

Keywords: animal emotions, jealousy, relationships, aggression, empathy

Christine Webb, Postdoctoral Fellow in the Center for Advanced Study in Ape and Human Evolution, Emory University, studies conflict resolution in humans and chimpanzees, including the evolutionary origins of reconciliatory behaviors and strategies. Website

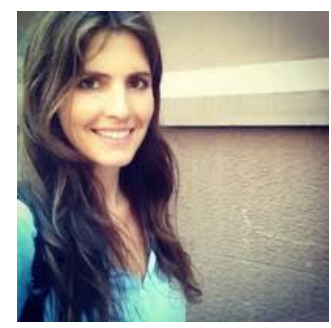

Frans de Waal is C. H. Candler Professor in the Psychology Department of Emory University, Director of the Living Links Center at Yerkes National Primate Research Center and Distinguished Professor at Utrecht University. His latest research concerns empathy and cooperation, inequity aversion and social cognition in chimpanzees,

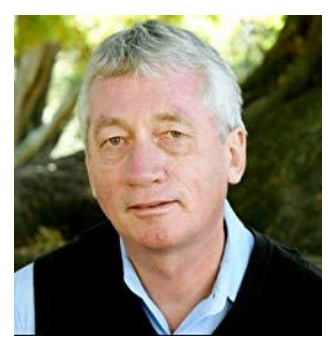
bonobos, and other species. Website

The scientific study of emotions in nonhuman animals has been beset with debates about definitions, measurement, adaptive function, and anthropomorphism - many of them recapitulated in the commentary on Cook et al.'s (2018) target article. These debates are often useful and constructive, but not if they start from the much less productive assumption that the study of animal emotions is inherently murky and messy. A distinction must be made between feelings (i.e., private states that we cannot observe in others) and emotions, which are manifested 
in behavior, physiology, brain activity, and other observables. These manifestations can be systematically measured across species, unlike associated felt experiences (de Waal, 2011). This is why many scientists insist on separating emotions from feelings (e.g., Adolphs \& Anderson, 2018), and assume that even in humans, some but by no means all emotions are being felt (Prinz, 2005). In the case of social emotions such as jealousy, we suggest that theoretical and empirical progress depends on identifying the social situations and relationships that precipitate them.

In the target article, Cook et al. used a non-invasive fMRI procedure to record amygdala activity in thirteen domestic dogs. More aggressive dogs, as measured by caregiver C-BARQ temperament reports, had higher amygdala activation upon watching their caregivers give food to a fake dog compared to when they just saw caregivers deposit food in a bucket. These results invited the authors to speculate about whether the observed pattern of neural activity corresponds in some way to human jealousy. As the question mark in the article's title implies, this is a tenuous link at best. The extent to which other species have emotions akin to human jealousy is nonetheless a timely question, and we applaud Cook et al. for jumpstarting the discussion. Whereas it is now rather well accepted that basic emotions - e.g., fear, anger, sadness, and joy - are ubiquitous across the animal kingdom, the presence and distribution in animals of more 'complex' emotions, including shame, contempt, jealousy, and empathy, remains contested. Pet owners rarely hesitate to ascribe such emotions to their pets, but scientists have been trained to avoid such descriptions. Many scientists (including several who commented on the target article such as Marazziti, 2018) would maintain that these emotions are based on abstract cognitive capacities that are unique to humans.

The origin of basic emotion theory (BET) is Ekman's (1992) work on human facial expressions. This is an extremely narrow framework for covering the evolution of all emotions, including those of species like dolphins and elephants, which barely show any facial expression. Due to its focus on the face, the BET does not even include 'love' as an emotion, even though there can be no doubt that love and attachment are found in all mammals, driven by a shared neuropeptide system (Insel \& Young, 2001; Panksepp, 1998).

A better framework may be one based on the adaptive functions of emotions (see also (Mobbs, 2018; Van Kleef, 2018). Since human social relations (focused on status, social networking, and family relations) are similar to those of other mammals, we may expect shared social emotions across species. Paramount to exploring jealousy's proximate and ultimate bases would be to investigate it in the context of social relationships. In this regard, Cook et al.'s research may not be making all the requisite distinctions. Like other commentators (Bräuer \& Amici, 2018; Denson, 2018; Jiang, Huttunen, \& Platt, 2018; Overall, 2018; Prato-Previde \& Valsecchi, 2018; Vonk, 2018), we wonder how the subject in this study perceived the fake dog especially in light of recent evidence that dogs do not perceive fake dogs as real social rivals (Prato-Previde et al., 2018b). Perhaps equally concerning is the fact that the relationship between the caregiver and the fake dog is stagnant - never varying in the extent to which it poses a threat to the existing bond between the subject dog and its caregiver. As suggested by several other commentators (Denson, 2018; Harmon-Jones \& Harmon-Jones, 2018; Vonk, 2018), manipulating the identity of the individual providing this potential 'rival' with food (such as having a condition in which a stranger administers the reward) would show whether amygdala activation is more pronounced for familiar vs. unfamiliar social partners, thereby offering a more formal test of the jealousy hypothesis. This is necessary because jealousy - as opposed to envy - concerns an 
established social relationship. It is an emotion that serves to protect existing social or sexual bonds against intrusion. As such, it should prompt reactions specific to familiar partners engaging with a potential rival. Did the dogs in this study see the fake dog as a rival intruder, and did they show the response specifically to their owners interacting with the fake dog?

It is also unclear whether the dogs were responding to a perceived threat to their relationship or simply to the loss of food to a rival dog (whether perceived as real or not). This would be like a child observing its parent offering a treat to an unfamiliar doll. Studying jealousy requires some potential perturbation of the existing parent-child (or owner-dog) relationship such as the caregiver offering attention and affection to a third party while ignoring the subject. It is possible that the provisioning of food is perceived by dogs as an affectionate (relationshipthreatening) gesture - but this possibility is not discussed. Thus, as noted above, the target article confounds jealousy and envy, a point that other commentaries have also highlighted (e.g., Abdai \& Miklósi, 2018; Denson, 2018; Harmon-Jones \& Harmon-Jones, 2018; Zentall, 2018). Whereas jealousy results from a perceived threat to an established relationship due to an intruder individual, envy emerges when one individual covets some resource that another individual has (Parrot \& Smith, 1993); as such, it is the emotion in which inequity aversion is likely rooted (as per Brosnan \& Waal, 2014).

Several of the above concerns were addressed in a recent study by Abdai et al. (2018), who used real dogs (familiar and unfamiliar to the subject) and non-social objects as potential rivals. In their experiment, owners focused attention on the test dogs and objects while ignoring their own subject dogs. Researchers recorded subjects' behaviors, including attempts to separate caregivers from the intruder dogs. They found that dogs showed such jealous behavior more toward social partners than toward non-social ones. In their commentary on Cook et el.'s target article, Abdai \& Miklósi (2018) acknowledge that further control conditions (e.g., testing with a stranger instead of owner, as above) would be necessary to deduce that jealousy was present. (Note also that they intentionally refer to jealous behavior, rather than to jealousy as a putative emotional state.)

Judging by publications in the last year alone, it seems that empirical investigation of jealousy in other species is on the rise (Abdai et al., 2018; Baniel et al., 2018; Cook et al., 2018; Prato-Previde et al., 2018a,b). Thus begins a new conversation about the reach of animal emotions, and thereby about the extent of human uniqueness. Provocative studies like Cook et al.'s lend themselves to an ongoing dialogue about animal capacities in general - one that inevitably elicits debate as well as skepticism. We have seen emotional capacities like empathy undergoing similar iterations: first rejection or indifference, then slow acceptance. Today empathy is used to describe and explain animal behavior quite broadly: It is no longer between quotation marks, nor followed by question marks; it is no longer 'empathy-like,' or 'protoempathy': just empathy. Resistance to this term waned in part thanks to the behavioral similarities between nonhuman animal and human expressions of empathy. Reports of animal consoling and helping behaviors - and particularly evidence that these behaviors vary across different social relationships - made the empathy hypothesis increasingly compelling (Bartal et al., 2011; Clay \& de Waal, 2013; Langford et al., 2006; Preston \& de Waal, 2002). This view was later bolstered by the discovery of neurological parallels with human empathy (Burkett et al., 2016; de Waal \& Preston, 2017). 
As this brief history exemplifies, neuroscience and physiology facilitate attempts to link human and nonhuman animal emotions. Non-invasive techniques like Cook et al.'s are valuable for a number of reasons, including their resemblance to protocols applied to human subjects. If similar behavioral reactions in related species are accompanied by similar neural processes and similar physiology, the most parsimonious explanation is homology (i.e., shared evolution). The concerns raised by commentators about whether amygdala activation is specific to jealousy (Adolphs, 2018; Harmon-Jones \& Harmon-Jones, 2018; Horowitz et al., 2018; Morris, 2018; Vonk, 2018) are readily acknowledged by Cook et al. in their target article and inspire relevant questions for future research. Comparisons with human jealousy using fMRI and other neurological measures can strengthen or weaken the evidence for homology.

When emotions are treated as theoretical constructs that explain behavior, we bypass the expectation that they must be felt experiences. Determining whether two people (or two dogs, or a dog and a person) feel jealous in the same way remains beyond the scope of modern science. Nor does the fact that humans can verbalize their private experiences necessarily make the study of human emotion more reliable: one could even argue the opposite in the case of emotions with high social salience such as empathy and jealousy. Studying jealousy within its appropriate social context will help generate and test hypotheses that do not rely on subjectivity. Thus, while it is important to get variables and definitions straight, there is nothing murky or messy about this effort. Science already deals with many unobservables such as the Big Bang and Continental Drift. We have theoretical constructs to translate the world around us, and jealousy, too, can serve as one. Appreciating the dependencies between social emotions and the social situations and relationships that precipitate them may represent a key step forward in this effective translation.

\section{References}

Abdai, J., \& Miklósi, Á. (2018). Displaying jealous behavior versus experiencing jealousy. Animal Sentience 22(21).

Abdai, J., Baño Terencio, C., Pérez Fraga, P., \& Miklósi, Á. (2018). Investigating jealous behaviour in dogs. Scientific Reports, 8(1), 1-8.

Adolphs, R. (2018). What would we like to know by imaging the brains of dogs? Animal Sentience 22(14).

Adolphs, R., \& Anderson, D. J. (2018). The Neuroscience of Emotion: A New Synthesis. Princeton, NJ: Princeton University Press.

Baniel, A., Cowlishaw, G., \& Huchard, E. (2018). Jealous females? Female competition and reproductive suppression in a wild promiscuous primate. Proceedings of the Royal Society B: Biological Sciences, 285(1886).

Bartal, I. B. A., Decety, J., \& Mason, P. (2011). Helping a cagemate in need: Empathy and pro-social behavior in rats. Science, 334(6061), 1427-1430.

Bräuer, J., \& Amici, F. (2018). Fake or not: Two prerequisites for jealousy. Animal Sentience 22(18).

Brosnan, S. F., \& De Waal, F. B. M. (2014). Evolution of responses to (un)fairness. Science, 346(6207), 17.

Burkett, J. P., Andari, E., Curry, D. C., de Waal, F. B. M., \& Young, L. J. (2016). Oxytocin-dependent consolation behavior in rodents. Science, 351(6271), 375-378.

Clay, Z., \& de Waal, F. B. M. (2013). Bonobos respond to distress in others: Consolation across the age spectrum. PLOS ONE, 8(1), e55206.

Cook, P., Prichard, A., Spivak, M., \& Berns, G. S. (2018). Jealousy in dogs? Evidence from brain imaging. 
Animal Sentience 22(1).

de Waal, F. B. M. (2011). What is an animal emotion? Annals of the New York Academy of Sciences, 1224, 191-206.

de Waal, F. B. M., \& Preston, S. D. (2017). Mammalian empathy: Behavioral manifestations and neural basis. Nature Reviews Neuroscience, 18, 498-509.

Denson, T. F. (2018). Inferring emotion from amygdala activation alone is problematic. Animal Sentience 22(9).

Ekman, P. (1992). An argument for basic emotions. Cognition and Emotion, 6(3-4), 169-200.

Harmon-Jones, E., \& Harmon-Jones, S. K. (2018). On jealousy, envy, sex differences and temperament in humans and dogs. Animal Sentience 22(8).

Horowitz, A., Franks, B., \& Sebo, J. (2018). Fill-in-the-blank-emotion in dogs? Animal Sentience 22(20).

Insel, T. R., \& Young, L. J. (2001). The neurobiology of attachment. Nature Reviews Neuroscience, 2, 129136.

Jiang, Y., Huttunen, A. W., \& Platt, M. L. (2018). Can a dog be jealous? Animal Sentience 22(11).

Langford, D. J., Crager, S. E., Shehzad, Z., Smith, S. B., Sotocinal, S. G., Levenstadt, J. S., Chanda, M. L., Levitin, D. J., \& Mogil, J. S. (2006). Social modulation of pain as evidence for empathy in mice. Science, 312(5782), 1967-1970.

Marazziti, D. (2018). Only the human brain has the cognitive capacity for jealousy. Animal Sentience 22(19).

Mobbs, D. (2018). What can the social emotions of dogs teach us about human emotions? Animal Sentience 22(5).

Morris, P. (2018). Limits of neuroscience. Animal Sentience 22(10).

Overall, K. L. (2018). Dogs aren't jealous - they are just asking for accurate information. Animal Sentience 22(17).

Panksepp, J. (1998). Affective Neuroscience: The Foundations of Human and Animal Emotions. New York, NY: Oxford University Press.

Parrot, W. G., \& Smith, R. H. (1993). Distinguishing the experiences of envy and jealousy. Journal of Personality and Social Psychology, 64(6), 906-920.

Prato-Previde, E., \& Valsecchi, P. (2018). What is it like to be a jealous dog? Animal Sentience 22(16).

Prato-Previde, E., Nicotra, V., Fusar Poli, S., Pelosi, A., \& Valsecchi, P. (2018a). Do dogs exhibit jealous behaviors when their owner attends to their companion dog? Animal Cognition, 21(21), 703-713.

Prato-Previde, E., Nicotra, V., Pelosi, A., \& Valsecchi, P. (2018b). Pet dogs' behavior when the owner and an unfamiliar person attend to a faux rival. PLOS ONE, 13(4), 1-17.

Preston, S. D., \& de Waal, F. B. M. (2002). Empathy: Its ultimate and proximate bases. Behavioral and Brain Sciences, 25(1), 1-72.

Prinz, J. (2005). Are emotions feelings? Journal of Consciousness Studies, 12, 9-25.

Van Kleef, G. A. (2018). Emotional reactions in non-human animals and social-functional theories of emotion. Animal Sentience 22(12).

Vonk, J. (2018). Researchers, not dogs, lack control in an experiment on jealousy. Animal Sentience 22(2). Zentall, T. R. (2018). Jealousy, competition, or a contextual cue for reward? Animal Sentience 22(4). 